\title{
Segmantasyon yapmadan patolojik kalp sesi kayıtlarının tespiti için bir örüntü sınıflandırma algoritması
}

\section{Abdulnasir YILDIZ}

Dicle Üniversitesi, Elektrik Elektronik Mühendisliği Bölümü, Diyarbakır abnayil@dicle.edu.tr ORCID: 0000-0002-1432-8360,Tel: (412) 2411000

\author{
Hasan ZAN* \\ Mardin Artuklu Üniversitesi, Meslek Yüksekokulu, Mardin \\ hasanzan@artuklu.edu.tr ORCID:0000-0002-8156-016X
}

Geliş: 30.10.2018, Kabul Tarihi: 28.11.2018

Öz

Bu çalışmada, altı adet veri bankasından alınan kalp sesi kayıtlarına segmentasyon uygulamadan $k$-En Küçük Komşuluk (kNN), Destek Vektör Makinesi (DVM) ve sinıflandırıcı metotları topluluğu kullanarak sınıflandırmaya yarayan bir algoritma geliştirilmesi amaçlanmıştır. Altı aşamadan oluşan algoritmanın ilk aşaması olan Önişlem aşamasında sinyaller sivri uçlarından arındırılmış ve ardından normalize edilmiştir. İkinci aşama olan Özellik çıkarma-1 aşamasında, sinyalin çeşitli zaman ve frekans özellikleri çıkarılarak üçüncü aşamadaki veri bankası sinıflandırıcının eğitilmesinde ve test edilmesinde kullanılmıştır. Üçüncü aşama olan veri bankası sınıflandırması aşamasında, her veri bankası oluşturulurken kullanılan cihazların, kayıt yeri ve ortamının farklılı̆̆ının negatif etkilerini azaltmak ve her veri bankası için farklı özellikler ile sinıflandırıcılar kullanmak amacıyla kalp sesi kayıtları veri bankalarına göre sinıflandırılmıştır. Dördüncü aşama olan Özellik Çıkarma-2 aşamasında veri bankalarına göre sinıflandırılan sinyallerin yine çeşitli zaman ve zaman-frekans özellikleri çıkarılmıştır. Beşinci aşamada her veri bankası için 3 farklı sınıflandırıcı ( $k N N, D V M$ ve sınıflandırıcı topluluğu) kullanılarak kayıtlar sinıflandırılmıştır. Algoritmanın son aşaması olan Oylama aşamasında, nihai sinıflandırma başarımını arttırmak amacıyla her kayıt için 3 farklı sınıflandırıcının çıkışları belli kurallara göre oylanarak kaydın sınıfi (patolojik veya normal) belirlenmiştir. Beşli çapraz doğrulama kullanılarak eğitilen ve test (tanı testi) edilen algoritmanın performansı ölçülürken doğruluk, duyarlılık, özgüllük, pozitif ve negatif yorum gücü ile ROC grafiğinin altında kalan alan gibi parametreler kullanılmıştır. En iyi performans sonuçları doğruluk: \%94.28, duyarlılık: \%87.97, özgüllük: \%87.97, pozitif yorum gücü: \%84.78, negatif yorum gücü: \%96.86 ve ROC eğrisi altında kalan alan: 0.919 şeklinde elde edildi. Elde edilen bu değerler daha önceki çalışmalar ile klyaslandiğında algoritmanın oldukça başarılı olduğu ve kalbin patolojik durumuna ilişskin uzman hekime ön tanı imkânı sunabileceği söylenebilir.

Anahtar Kelimeler: Kalp sesi; Fourier dönüşümü; DVM; kNN; Sinıflandırlcı metotları topluluğu; Siniflandirma;

* Yazışmaların yapılacağı yazar

DOI: 10.24012/dumf.476437 


\section{Giriş}

Kardiyovasküler bozukluklar veya kalp hastalıkları bir insanın kalp durumu hakkında bilgi veren genel bir terimdir. Kalp hastalıkları, dünyada artan ölümlerin ana kaynaklarından bir tanesidir. Her yıl Türkiye'de kalp hastalıkları yüzünden ölen insan sayısı diğer sebeplerden dolayı ölen insan sayısından daha fazladır. 2014 yılında ölen insan sayısının \% 25.61'lik kısmı kalp hastalıklarından dolayı öldüğü tahmin edilmektedir (WHO, 2018)

Kalp hastalıklarını tespit etmek amacıyla EKG, bilgisayarlı tomografi, efor testi ve MR gibi gelişmiş yöntemlerin yanı sıra kalp sesinin stetoskop yardımıyla hekimler tarafindan dinlenerek kalp sesindeki bozuklukların tespiti gibi basit yöntemler de kullanılmaktadır. Ayrıca son yıllarda kalp sesi kayıtlarını kullanarak sinyal işleme teknikleri ve makine öğrenmesi yardımıyla kişilerin kalp hastalıklarına sahip olup olmadığını tespit eden otomatik örüntü tanıma sistemleri geliştirilmeye çalışılmaktadır (Maglogiannis, 2009).

Elektronik stetoskop ile kaydedilip dijital sinyale dönüştürülen kalp sesine fonokardiyogram (PCG) denir (Zhongwei ve Samjin, 2006). Bu sinyaller kompleks, durağan olmayan sinyallerdir ve vücudun mekanik aktiviteleri sonucu meydana gelmekle beraber kalp hastalıklarını tespit etmede önemli bilgiler içerir (Lekram ve Abhishek, 2014).

PCG kayıtları dört tane kalp sesi bileşeninden (S1, S2, S3 ve S4) meydana gelebilir. Temel kalp sesleri olarak da adlandirılan birinci ve ikinci kalp sesleri (S1 ve S2) herhangi bir hastalığa sahip olmayan her kalpten duyulabilir. $\mathrm{Bu}$ sesler kalpteki kapakçıkların kapanıp açılması sonucu oluşur. S1'in başlangıcı ile S2'nin başlangıcı arasında kalan bölge sistol (kalbin kasılmas1) olarak adlandırılır. S2'nin başlangıcı ve diğer döngüdeki S1'in başlangıcı arasında kalan bölge ise diyastol (kalbin genişlemesi) olarak adlandırılır. Hastalıklı bir kalbe ait PCG kayıtlarında üçüncü ve dördüncü (S3 ve S4) kalp sesleri de duyulabilir (Johnston,
2007). Şekil 1'de tüm kalp seslerine sahip örnek bir PCG kaydı verilmiştir.

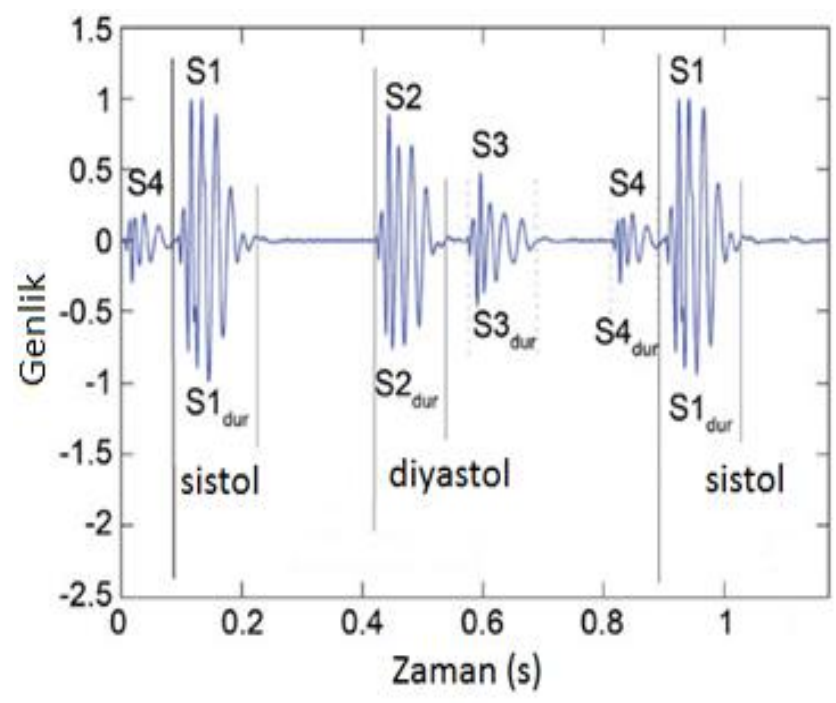

Şekil 1.Tipik bir kalp sesi sinyali

Kalp atımı sırasında duyulan olağan dışı seslere üfürüm denir. Üfürümler en yaygın görülen kalp anormalliklerinden biridir. Üfürümler ile kalp sesleri arasındaki temel fark üfürümlerin gürültülü ve daha uzun olmasıdır. Sistol (kalbin kasılması) aralığında meydana gelen üfürümler, sistolik üfürüm; diyastol (kalbin genişlemesi) aralığında meydana gelen üfürümler diyastolik üfürüm olarak sınıflandırılır (Nigam ve Priemer, 2007)

Literatürde yer alan kalp hastalıklarını tespit etmede kullanılan otomatik örüntü tanıma sistemleri genellikle önişlem, segmentasyon, özellik çıkarma ve sinıflandırma olmak üzere dört temel aşamadan oluşmaktadır (Nabih vd., 2017). Yapılan pek çok çalıșmanın önişlem aşamasında, sinyallere filtreleme, gürültüden arındırma ve normalizasyon gibi işlemler uygulanmıştır (Nabih vd., 2017). Kalp seslerinin alt kalp seslerine ayrılması işlemi olan segmentasyon aşamasında ise zarf, özellik, makine öğrenmesi ve saklı Markov modeli temelli metotlar kullanılmıştır (Liu vd., 2016). Özellik çıkarma aşamasında ise Fourier dönüşümü, dalgacık dönüşümü, mel frekansı kepstrum katsayıları, S dönüşümü, ayrık kosinüs dönüșümü, Choi-Williams dağılımı ve Shanon enerji gibi yöntemler kullanılmıştır (Nabih vd., 
2017). Algoritmanın son aşaması olan sınıflandırma aşamasında ise Yapay sinir ağları (YSA), DVM, kNN, siniflandirıcı metotları topluğu ve derin öğrenme gibi pek çok yöntem sınıflandırıcı olarak kullanılmıştır (Nabih vd., 2017).

Son 50 yıldır kalp sesi işaretlerinden kişinin kalp hastası olup olmadığının tespitine yönelik geliştirilen otomatik teşhis algoritmaların başarımı genelde belirli bir lokasyondan alınan, gürültüsüz ve az sayıda kalp sesi kaydı içeren veri setleri üzerinden test edilmiştir. Bu da farklı lokasyonlardan alınan, gürültülü ve çok fazla sayıda kayıt içeren bir veri seti üzerinden başarımı test edilmiş yüksek performanslı algoritmaların geliştirilmesi gerektiğini gösterir.

Bu çalışmada, PCG kayıtlarından kişinin kalp hastası olup olmadığını tespit eden zaman, zaman-frekans tabanlı işaret işleme ve makine öğrenmesi algoritmalarına dayalı bir örüntü sınıflandırma sistemi geliştirilmeye çalışılmıştır. Çalışmada, farklı veri bankalarından alınan PCG kayıtlarındaki farklılıkların olumsuz etkisini azaltmak amaciyla kayitlar veri bankasina göre ön siniflandırmaya tabi tutulmuştur. Veriler veri bankalarına göre sinıflandırıldıktan sonra segmentasyon işlemine tabi tutulmadan DVM, kNN ve siniflandırıc1 metotları topluluğu kullanılarak sınıflandırılmıştır.Geliştirilen sistemin başarım performansı altı adet veri bankasından elde edilen, farklı lokasyonlu ve gürültülü kayıtların da içeresinde yer aldığı ve toplamda 3240 kalp sesi kaydından oluşan bir veri seti üzerinden test edilmiştir. Elde edilen test sonuçları daha önce yapılmış olan benzer çalışmalar ile kıyaslanmıştır.

\section{Materyal ve Yöntem}

\section{Kullanılan Kalp Sesi Kayıtları}

Yapılan önceki çalışmaların çoğundaki en büyük eksiklik kullanılan verilerin kısıtlı sayıda ve gürültüsüz olmasıydı. Bu amaçla pek çok kurum tarafindan desteklenen physionet.org, geniş bir veri bankası oluşturmak ve dünyadaki araştırmacıları normal ve anormal PCG kayıtlarının sınıflandırılması konusunda çalışma yapmaları için teşvik etmek amacıyla 2016 yılında bir yarışma düzenledi. Yarışma kapsamında oluşturulan veri bankasının eğitim seti "physionet.org/challenge/2016" adresinden indirilebilir. Tablo 1'de veri bankaları ile ilgili detaylar yer almaktadir.

Tablo 1. Kullanılan verilere ilişkin detaylar

\begin{tabular}{lllllll}
\hline Veri Bankası & Denek Tipi & $\begin{array}{l}\text { Denek } \\
\text { Sayısı }\end{array}$ & Yaş & $\begin{array}{l}\text { Kayıt } \\
\text { Sayısı }\end{array}$ & $\begin{array}{l}\text { Kayıt Uzunluğu } \\
\text { (Saniye) }\end{array}$ & $\begin{array}{l}\text { Örnekleme } \\
\text { Frekansı }\end{array}$ \\
\hline MITHSDB & Normal & 38 & Bilinmiyor & 117 & $33 \pm 5$ & $44100 \mathrm{~Hz}$ \\
(a) & Anormal & 83 & Bilinmiyor & 292 & $33 \pm 5$ & $44100 \mathrm{~Hz}$ \\
AADHSDB & Normal & 121 & Bilinmiyor & 544 & 8 & $4000 \mathrm{~Hz}$ \\
(b) & Anormal & 30 & Bilinmiyor & 151 & 8 & $4000 \mathrm{~Hz}$ \\
AUTHHSDB & Normal & 11 & $29 \pm 8$ & 11 & $47 \pm 25$ & $4000 \mathrm{~Hz}$ \\
(c) & Anormal & 34 & $77 \pm 9$ & 34 & $56 \pm 34$ & $4000 \mathrm{~Hz}$ \\
TUTHSDB & Normal & 28 & Bilinmiyor & 174 & 15 & $4000 \mathrm{~Hz}$ \\
(g) & Anormal & 16 & Bilinmiyor & & 15 & $4000 \mathrm{~Hz}$ \\
UHAHSDB & Normal & 19 & $18-40$ & 19 & $14 \pm 5$ & $8000 \mathrm{~Hz}$ \\
(d) & Anormal & 36 & $44-90$ & 60 & $16 \pm 9$ & $8000 \mathrm{~Hz}$ \\
DLUTHSDB & Normal & 174 & $25 \pm 3$ & 338 & $209 \pm 78$ & $800-22050 \mathrm{~Hz}$ \\
(e) & Anormal & 335 & $60 \pm 12$ & 335 & $17 \pm 12$ & $8000 \mathrm{~Hz}$ \\
SUAHSDB & Normal & 79 & $56 \pm 16$ & 81 & $33 \pm 5$ & $8000 \mathrm{~Hz}$ \\
(f) & Anormal & 33 & $56 \pm 16$ & 33 & $33 \pm 5$ & $8000 \mathrm{~Hz}$ \\
SSHHSDB & Normal & 12 & Bilinmiyor & 12 & $36 \pm 12$ & $8000 \mathrm{~Hz}$ \\
(i) & Anormal & 23 & Bilinmiyor & 23 & $36 \pm 12$ & $8000 \mathrm{~Hz}$ \\
Toplam & - & 1072 & - & 2224 & - & - \\
\hline
\end{tabular}


Yarışma kapsamında Tablo 1'de verilen veri bankaları $2 \mathrm{kHz}$ örnekleme frekansı ile yeniden örneklenerek bir araya getirilmiş ve veriler eğitim ve test veri seti olarak ayrılmıştır. Sadece eğitim veri seti indirilebildiğinden bu çalışmada a, b. c. d, e ve $f$ olarak etiketlenen veri bankalarının eğitim veri seti olarak adlandırılan PCG kayıtları kullanılmıştır. Bu veri seti altı adet farklı veri bankasının birleşiminden oluşmaktadır. Veri seti 2575 'ü normal ve 665'si anormal olmak üzere toplamda 3240 adet PCG kaydı içermektedir. Mevcut çalışmamızda bu veri seti çalışma veri seti olarak adlandırılmıştır. Çalışmamızda geliştirilen algoritmanın performans değerlendirilmesinde 5-katlı çaprazlama doğrulama (5-fold cross validation) yöntemi kullanılmıştır. Bunun için çalışma veri setinden beş adet kopya oluşturulmuş, her kopya beş parçaya bölünmüştür. Oluşturulan beş parçanın dördü eğitim, bir ise test (tanı testi) için kullanılmıştır. Son olarak beş tanı testi sonuçlarının ortalaması alınarak algoritmanın performansı hesaplanmıştır. Çapraz doğrulamanın her adımında kullanılan kayıtlara ilişkin detaylar Tablo 2'te verilmiştir.

Tablo 2. Çapraz doğrulama için eğitim veri seti ve test veri seti

\begin{tabular}{llll}
\hline Veri Seti & Alt Veri Seti & Normal & Anormal \\
\hline \multirow{6}{*}{ Eğitim } & $\mathrm{a}$ & 94 & 234 \\
& $\mathrm{~b}$ & 309 & 84 \\
& $\mathrm{c}$ & 6 & 19 \\
& $\mathrm{~d}$ & 22 & 22 \\
& $\mathrm{e}$ & 1566 & 146 \\
& $\mathrm{f}$ & 64 & 27 \\
& Toplam & 2061 & 532 \\
\hline \multirow{6}{*}{ Test } & $\mathrm{a}$ & 23 & 58 \\
& $\mathrm{~b}$ & 77 & 20 \\
& $\mathrm{c}$ & 1 & 5 \\
& $\mathrm{~d}$ & 5 & 6 \\
& $\mathrm{e}$ & 392 & 37 \\
& $\mathrm{f}$ & 16 & 7 \\
& Toplam & 514 & 133 \\
\hline
\end{tabular}

\section{Algoritmanın Yapısı}

Matlab R2017b programında yazılmış olan algoritma Önişlem, Özellik Çıkarma-1, Veri Bankası Sınıflandırması, Özellik Çıkarma-2, Nihai Sınıflandırma ve Oylama olmak üzere altı aşamadan oluşmaktadır. Algoritmanın blok diyagramı Şekil 2'de verilmiştir.

\section{Önişlem}

$\mathrm{Bu}$ aşamada gürültüden kaynaklı sivri uçları PCG kayıtlarından ayıklamak için Schmidt ve diğerleri (2010) tarafindan geliştirilen bir yöntem kullanılmıştır. Dört adımdan oluşan bu yöntemin işlem adımları sırasıyla aşağıda verilmiştir;

1) Sinyal 500 ms'lik bölütlere ayrılır.

2) Her bölütteki maksimum mutlak genlik (MMG) bulunur.

3) Eğer en az bir tane MMG, tüm MMG'lerin ortanca değerinin üç katını geçerse a'dan e'ye kadar olan işlemler uygulanır, yoksa dördüncü adıma geçilir.

a) En yüksek $M M G$ değerine sahip bölüt seçilir.

b) Seçilen bölütte sivri ucun tepe noktası MMG'nin konumu olarak tanımlanır.

c) Sivri ucun başlangıç noktası, MMG'den önce sinyalin en son sıfırdan geçtiği nokta olarak tanımlanır.

d) Sivri ucun son bulduğu nokta MMG'den sonra sinyalin ilk defa sıfırdan geçtiği nokta olarak tanımlanır.

e) Tanımlanan sivri uç sıfırlar ile değiştirilir.

4) İşlem tamamlanır.

Belirtilen yöntemin örnek bir PCG kaydına uygulanması Şekil'3de gösterilmiştir. Önişlem aşamasında gerçekleştirilen bir diğer işlem normalizasyon işlemedir. Normalizasyun deneğe ait özelliklerin kayıtlardan arındırılması için başvurulan bir işlemdir. $\mathrm{Bu}$ işlem için çalışmada minmaks normalizyon yöntemi kullanılmıştır. 


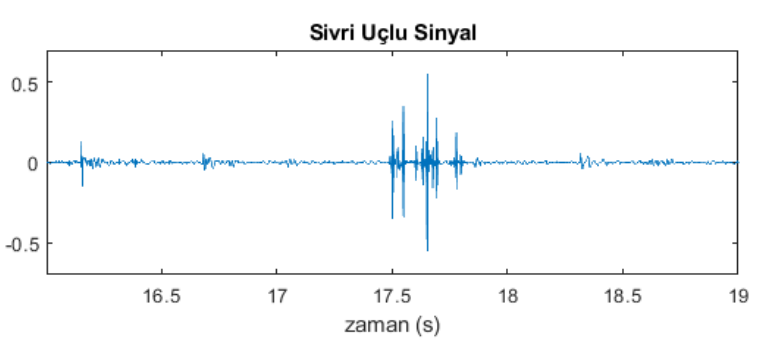

Sivri Ucu Yokedilmiş Sinyal

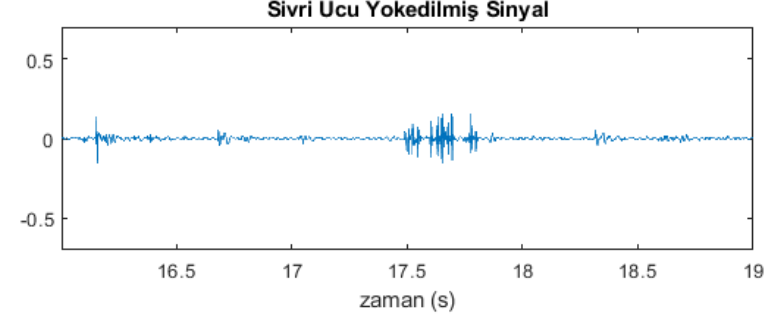

\section{Özellik Çıkarma-1}

$\mathrm{Bu}$ aşamada, sinyalin zaman uzayına ve Hızlı Fourier Dönüşümü (HFD) kullanılarak elde edilen frekans uzayına $(0-200 \mathrm{~Hz}$ ile 800 $1000 \mathrm{~Hz}$ frekans aralıkları) ait istatistiksel özellikleri çıkarılmıştır (minimum, maksimum, ortalama, medyan, basıklık, çarpıklık, etkin değer ve etkin değerin maksimum değere oranı olmak üzere $8 \times 4=$ 24 adet özellik).

Şekil 3. Sivri uçlu ve sivri ucu yok edilmiş iki PCG kaydl

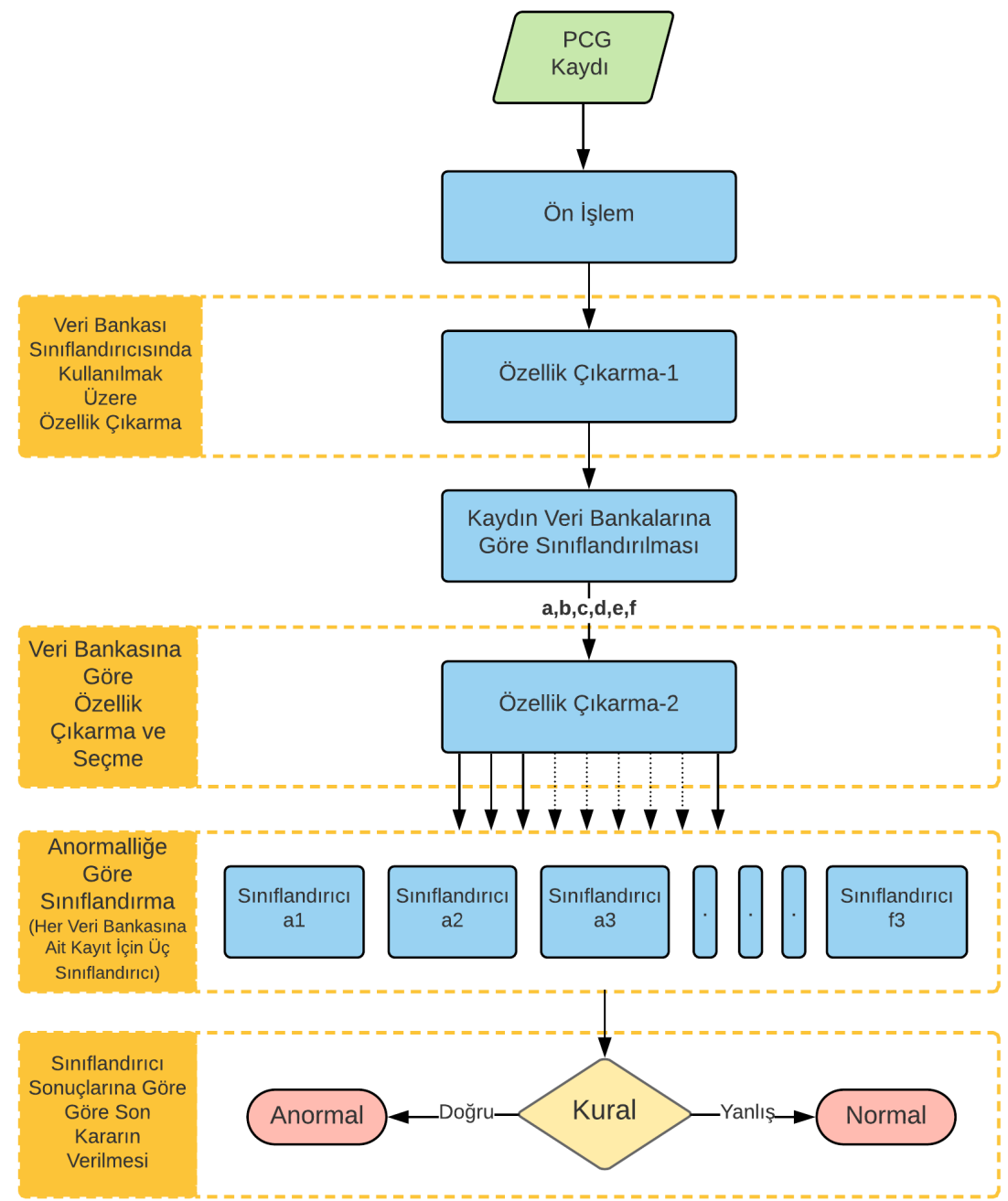

Şekil 2. Önerilen algoritmanın blok diyagramı

\section{Veri Bankası Sınıflandırması}

$\mathrm{Bu}$ aşamanın amacı altı adet veri bankasından alınan kalp sesi kayıtlarının altı sınıfa ayrılmasıdır. Böylece sonraki adımlarda her veri bankasına ait kayıtlar için farklı özellik seçilebilmesi ve nihai sınıflandırma aşamasında her veri bankası için ayrı sınıflandırıc1 kullanılması mümkün olmaktadır. 
Detaylı açıklaması aşağıda verilmiş olan sinıflandırıcı metotları topluluğu veri bankası sınıflandırıcısı olarak kullanılmıştır. $\mathrm{Bu}$ sınıflandırıcı beşli çapraz doğrulamanın her adımında her biri 24 adet özelliğe sahip 2590 adet PCG kaydı ile eğitilmiştir. Sinıflandırıciya ait parametreler deneme yanılma yolu ile bulunmuştur. $\mathrm{Bu}$ aşamada kullanılan siniflandirıcı verileri altı sinıfa \%98.14'lük bir doğruluk ile sinıflandırmıştır.

Tablo 3. Veri bankası siniflandirıcisina ait detaylar

\begin{tabular}{ll}
\hline $\begin{array}{l}\text { Sinıflandırıcı } \\
\text { Türü }\end{array}$ & $\begin{array}{l}\text { Sinıflandırıcı } \\
\text { Metotları Topluluğu }\end{array}$ \\
\hline Algoritma & AdaBoostM2 \\
\hline $\begin{array}{l}\text { Zayıf } \\
\text { Sınıflandırıcı } \\
\text { Türü }\end{array}$ & Karar Ağacı \\
\hline $\begin{array}{l}\text { Sınıflandırıcı } \\
\text { Sayısı }\end{array}$ & 487 \\
\hline Öğrenme Oranı & 0,4591 \\
\hline
\end{tabular}

\section{a) Sinıflandırıcı Metotları Topluluğu}

Pek çok araştırmacı çok sayıda sınıflandırıcının tahminlerini birleştirerek tek bir sınıflandırıcı oluşturma tekniğini incelemiştir. Elde edilen sinıflandırıcı, yani topluluk, genellikle bu topluluğu oluşturan her bir sinıflandırıcıdan daha yüksek bir doğruluğa sahip olur. $\mathrm{Bu}$ yöntemin temel prensibi bir grup zayıf sınıflandırıcıyı çeşitli algoritmalar kullanarak bir araya getirip güçlü bir sınıflandırıcı oluşturmaktır. Sınıflandırıcı topluluğu oluşturulurken en çok kullanılan algoritmalar Adaboost ailesi algoritmaları (arttırma, boosting) ve bagging (özyükleme bütünleştirmesi, bootstrap aggregation) algoritmasıdır. $\mathrm{Bu}$ algoritmalar ile beraber en çok kullanılan zayıf sınıflandırıcı ise karar ağacıdır (Zhukov vd., 2017).

Boosting ile yeniden ağırlıklandırılmış eğitim verilerine siniflandirma algoritmalarından bir tanesi sira ile uygulanır ve elde edilen sonuçlar ağırlıkları ile beraber oylanarak tek bir sinıflandirma sonucu elde edilir.

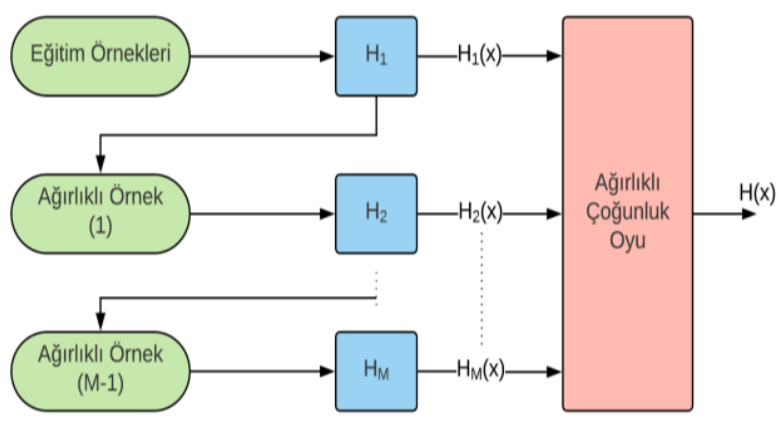

Şekil 4. Boosting algoritmalarının genel yapist

Bootstrap, genel amaçlı ve örnek temelli bir istatistiksel yöntemdir. $\mathrm{Bu}$ yöntemde, temel bir veri setinden rastgele, her seferinde eşit sayıda ve tekrar yerine koymak suretiyle veri alınarak ayrık eğitim verileri oluşturulur. Bagging, bootstrap örneklemesi kullanılarak sınıflandırıcıların doğruluğunu arttırmak için kullanılan bir tekniktir. Mevcut çalışmada PCG kayıtlarının hangi veri bankasına ait olduğunu belirlemek için kullanılan sınıflandırıcı metotlar topluluğun ilişkin detaylar Tablo 3'de verilmiştir.

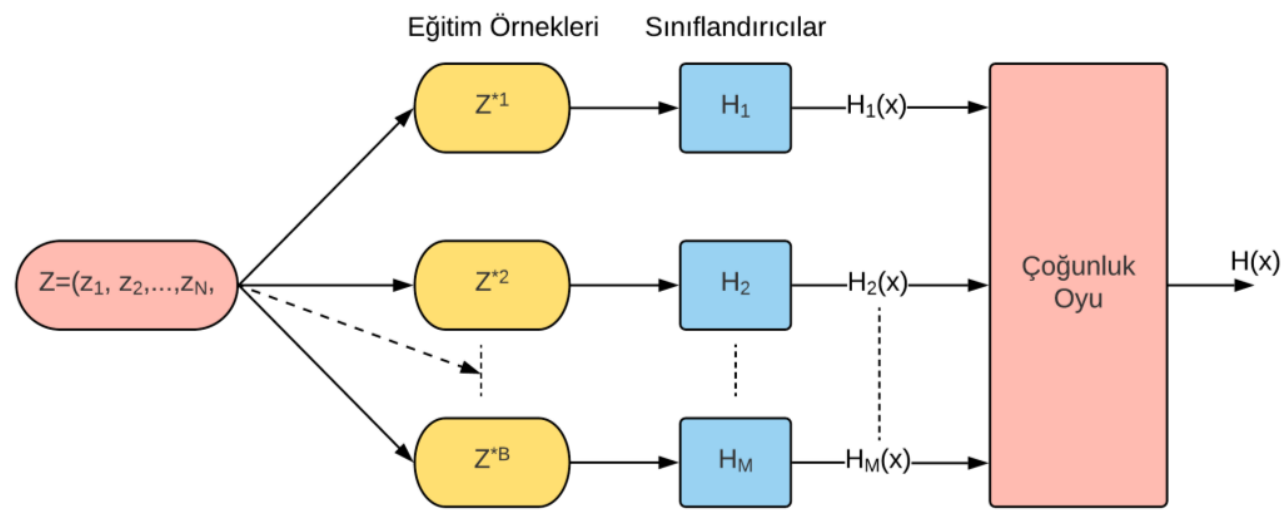

Şekil 5. Bagging algoritmasının genel yapısı 


\section{Özellik Çıkarma-2}

$\mathrm{Bu}$ aşamada PCG kayıtlarının "Db4" dalgacığı ile elde edilen 3 . ve 4 . seviye detay ile yaklaşım katsayılarının, mel frekansı kepstrum katsayılarının, sinyalin zaman ve frekans uzayının aşağıda belirtilen özellikleri çıkarılmıştır.

Bütün veri bankaları için aynı sayıda olmak üzere her veri bankası için toplamda 169 adet özellik çıkarılmıştır. Çıkarılan özellik sayısını azaltmak için açıklaması aşağıda verilen ardışık ileri yönde özellik seçme algoritması kullanilarak siniflandirma performansina olumsuz etkisi olan ve sinıflandirma performansına hiçbir etkisi olmayan gereksiz özellikler elemine edilmiştir. Özellik seçme sonrası veri bankaları için seçilen özellik sayısı Tablo 5'te verilmiştir.

Tablo 4. Çıkarılan özellikler

\begin{tabular}{lcccc}
\hline Özellik & $\begin{array}{l}\text { Zaman } \\
\text { Uzayı }\end{array}$ & $\begin{array}{l}\text { Hızlı } \\
\text { Fourier } \\
\text { Dönüşümü }\end{array}$ & $\begin{array}{l}\text { Ayrık dalgacık dönüşümü: 3. ve } \\
\text { 4. Seviye Yaklaşım ve Detay } \\
\text { Katsayıları (Db4 dalgacığı) }\end{array}$ & $\begin{array}{l}\text { Mel Frekansı Kepstrum } \\
\text { Katsayıları } \\
\text { (13 katsayı+1 filtre enerjisi) }\end{array}$ \\
\hline Etkin değer & $\checkmark$ & $\checkmark$ & $\checkmark$ & $\checkmark$ \\
Sifırdan geçme oranı & $\checkmark$ & $\checkmark$ & $\checkmark$ & X \\
Basıklık & $\checkmark$ & $\checkmark$ & $\checkmark$ & $\checkmark$ \\
Çarpıklık & $\checkmark$ & $\checkmark$ & $\checkmark$ & $\checkmark$ \\
Ortalama & $\checkmark$ & $\checkmark$ & $\checkmark$ & $\checkmark$ \\
Standart Sapma & $\checkmark$ & $\checkmark$ & $\checkmark$ & $\checkmark$ \\
Varyans & $\checkmark$ & $\checkmark$ & $\checkmark$ & $\checkmark$ \\
Entropi & $\checkmark$ & $\checkmark$ & $\checkmark$ & $\checkmark$ \\
Maksimum & $\checkmark$ & $\checkmark$ & $\checkmark$ & $\checkmark$ \\
Medyan & $\checkmark$ & $\checkmark$ & $X$ & $\times$ \\
Toplam harmonik & $X$ & $\checkmark$ & $X$ & $X$ \\
bozulma & & & & \\
\hline
\end{tabular}

Tablo 5'ten de görülebileceği gibi veri bankası $b$ ve c için seçilen özellik sayısı ilk başta çıkarılan özellik sayısı ile aynıdır. Çünkü özellik seçmeden sonra Veri bankası-b için performans düşmüştür. Veri bankası-c için ise özellik seçmeden önce bile tam performans elde edildiğinden özellik seçmeye gerek kalmamıştır.

Tablo 5. Özellik seçme sonrası özellik sayıları

\begin{tabular}{ll}
\hline Veri Bankası & Özellik Sayısı \\
\hline a & 9 \\
b & 169 \\
c & 169 \\
d & 4 \\
e & 6 \\
f & 7 \\
\hline
\end{tabular}

a) İleri Yönde Özellik Seçme Algoritması

Özellik seçmenin amacı, çıkarılan özellik kümesinden daha az siniflandırma hatası elde edilebilecek bir alt küme seçilmesidir. İleri yönde özellik seçme algoritması boş bir alt küme ile başlar. Sonra alt kümeye yeni bir özellik eklenir ve aday alt küme oluşturulur. Aday alt küme, değerlendirme kriterine göre değerlendirilir. Değerlendirme sonucu özellik eklenmeden önceki değerlendirme sonucundan daha iyi ise özellik tutulur, değil ise çıkarılır. Daha sonra alt kümeye özellik kümesinden yeni bir özellik eklenerek aynı işlemler tekrarlanır. Durma kriterine ulaşıncaya veya özellik kümesinde özellik kalmayana kadar aynı işlemler tekrarlanır (Jain ve Zongker, 1997). Algoritmanın blok diyagramı Şekil 6'da verilmiştir. 


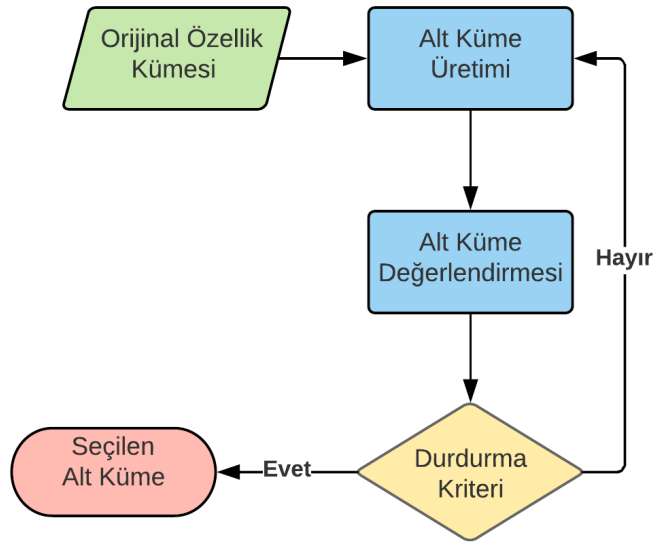

Şekil 6. Illeri yönde özellik seçme algoritması

\section{Nihai Sınıflandırma}

Algoritmanın bu adımında, patolojik kalp sesi kayıtlarını tespit etmek amacıyla her veri bankası için özel olarak eğitilen DVM, kNN ve siniflandırıcı metotları topluluğu (SMT) olmak üzere veri bankası başına üç adet, toplamda ise 18 adet siniflandirici kullanılmıştır. Sinıflandırıcılara ilişkin deneme yanılma yoluyla bulunan parametreler Tablo 6'da verilmiştir. Veri bankası-a için sınıflandırıcıların eğitilmesi ve test edilmesine ilişkin blok diyagramı Şekil 7'de verilmiştir. Bütün veri bankaları için aynı işlem adımları takip edilmiştir.

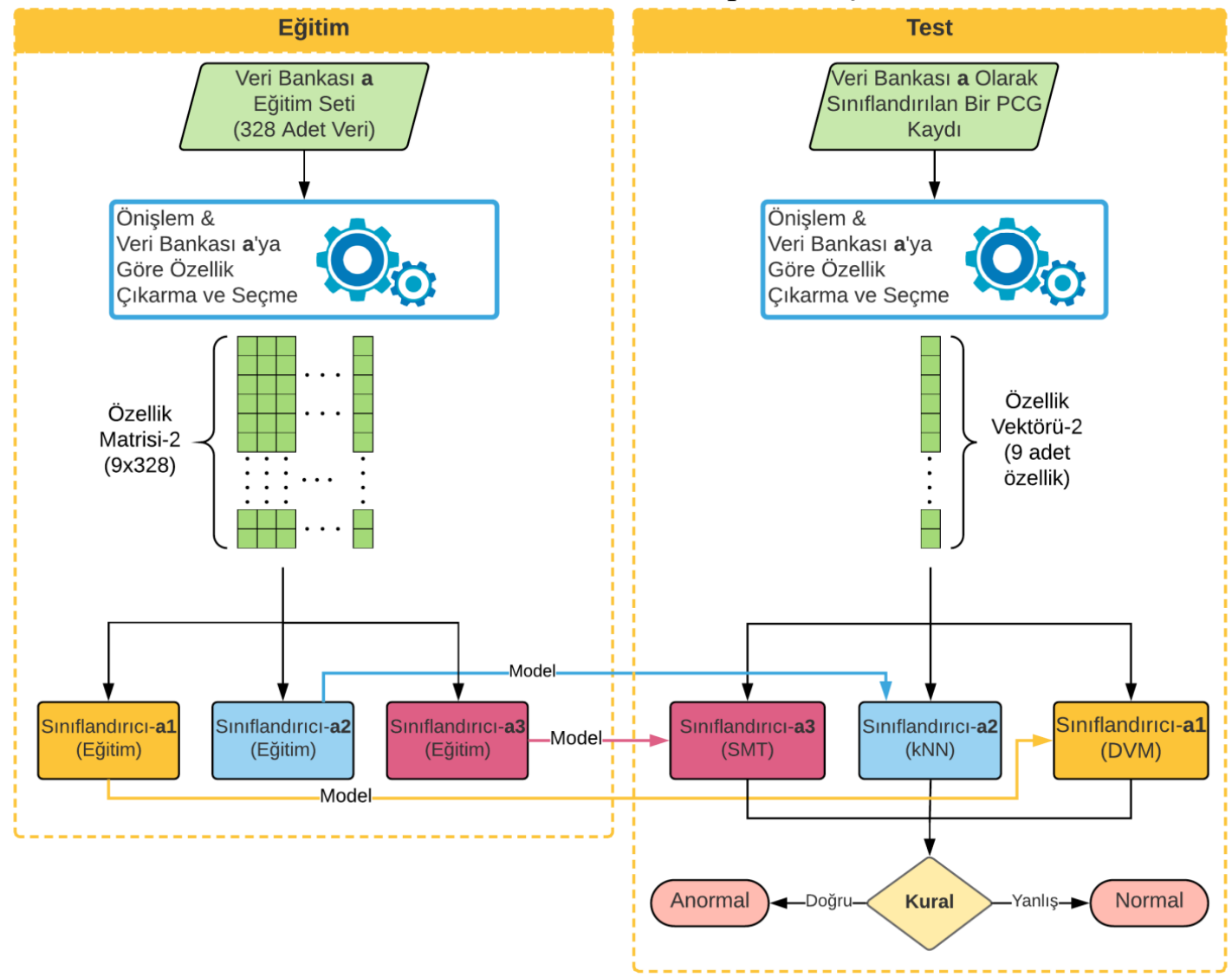

Şekil 7. Sinıflandırıcıların eğitilmesi ve test edilmesi

Tablo 6. Sinıflandirıcılara ilișkin detaylar

\begin{tabular}{ccccccc}
\hline Parametre & \multicolumn{5}{c}{ Veri Bankası } \\
\cline { 2 - 6 } & $\mathbf{a}$ & $\mathbf{b}$ & $\mathbf{c}$ & $\mathbf{d}$ & $\mathbf{e}$ & $\mathbf{f}$ \\
\hline $\begin{array}{c}\text { Çekirdek } \\
\text { Fonksiyonu } \\
\text { Çekirdek } \\
\text { Ölçeği }\end{array}$ & gaussian & gaussian & polynomial & polynomial & polynomial & gaussian \\
Polinom & 999.520 & 85.645 & - & - & - & 244.311 \\
Derecesi & - & - & 3 & 2 & 2 & - \\
Kutu Sınırı & 7.548 & 976.000 & 4.735 & 541.412 & 0.065 & 946.500 \\
\hline
\end{tabular}




\begin{tabular}{|c|c|c|c|c|c|c|}
\hline \multirow{2}{*}{ Parametre } & \multicolumn{6}{|c|}{ Veri Bankası } \\
\hline & $\mathbf{a}$ & b & c & d & e & f \\
\hline $\begin{array}{l}\text { Komşu } \\
\text { Sayısı }\end{array}$ & 38 & 1 & 8 & 11 & 1 & 25 \\
\hline Uzaklık & minkowski & kapsamlı & minkowski & seuclidean & mahalonobis & chebychev \\
\hline $\begin{array}{l}\text { Uzaklık } \\
\text { Ağırlığı }\end{array}$ & Karesel-ters & Öklit-ters & eşit & eşit & ters & eşit \\
\hline Üs & 0.645 & - & 2 & - & - & - \\
\hline Metot & bag & bag & bag & gentleboost & gentleboost & logitboost \\
\hline Sinıflandırıcı & ağaç & ağaç & ağaç & ağaç & ağaç & ağaç \\
\hline $\begin{array}{l}\text { Sinıflandirıcı } \\
\text { Sayısı }\end{array}$ & 496 & 45 & 265 & 10 & 338 & 337 \\
\hline $\begin{array}{c}\text { Öğrenme } \\
\text { Oranı }\end{array}$ & 1 & 1 & 1 & 0.991 & 0.002 & 0.001 \\
\hline
\end{tabular}

\section{a) $k N N$}

kNN metodu kümeleme ve siniflandırma uygulamalarda geniş bir şekilde kullanılan basit bir makine öğrenmesi tekniğidir. $\mathrm{Bu}$ yöntemde, sınıfları bilinen eğitim veri seti kullanılarak test veri seti aynı sınıflara girecek şekilde sınıflandırılır. Bunun için eğitim veri setinin her bir noktasina en yakın $\mathrm{k}$ adet test eğitim seti noktası belirlenir. Daha sonra çoğunluk oyuna göre test veri setinin sınıfları belirlenir (Lubaib ve Ahammed, 2015). kNN algoritmasının işlem adımları şu şekildedir:

1) Verileri yükle.

2) $k$, yani komşu sayısını belirle.

3) Tahmin edilen sınıfları elde etmek için birden eğitim setindeki örnek sayısına kadar iterasyon yap.

a) Test verileri ile eğitim verisinin her bir sütunu arasındaki uzaklığı uzaklık fonksiyonu ile hesapla.

b) Hesaplanan uzaklıkları küçükten büyüğe doğru sırala.

c) Sıralanmıș diziden $\mathrm{k}$ adet sütun al.

d) $\mathrm{Bu}$ sütunlarda en sık karşılaşılan siniflari al.

e) Tahmin edilen sınıfları elde et.

\section{b) $D V M$}

DMM ikili sınıflandırma için kullanılan makine öğrenmesi tekniğidir. DVM'nin temelleri Vapnik (1995) tarafindan atılmıştır. DVM'nin temeli pozitif ve negatif örnekler arasındaki ayrımı en iyi şekilde yapan bir hiper düzlemin bulunmasıdır. Hiper düzlem bulunurken düzlemin her iki sinıfa olan uzaklık maksimize edilmeye çalışılır. Eğer örnekler lineer olarak ayrılamıyorsa örneklere çeşitli çekirdek dönüşümleri uygulanarak boyut sayısı arttırılarak hiper düzlem bulunur. $\mathrm{Bu}$ hiper düzleme en yakın olan noktalara yani sinıflandırılması en zor olan noktalara destek vektörleri denir. Eğitim verileri kullanılarak hiper düzlem bulunduktan sonra test verileri bu düzlem kullanılarak sinıflandirılır (Lubaib ve Ahammed, 2015). İki boyutlu eğitim veri seti için bulunan hiper düzlemin geometrik gösterimi Şekil 8'de verilmiştir.

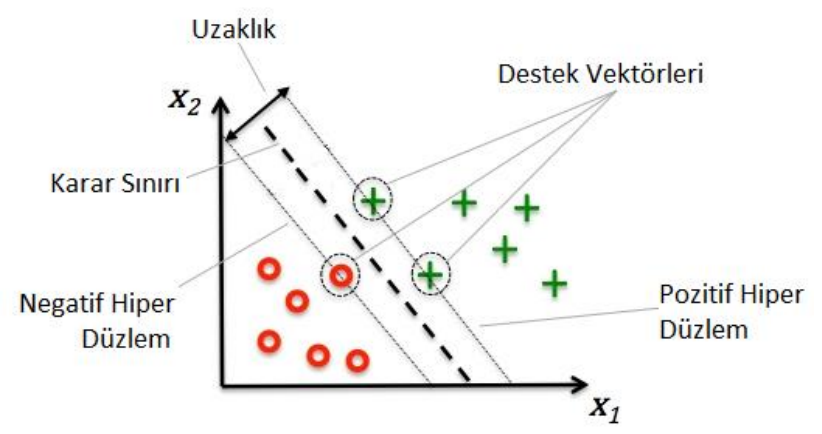

Şekil 8. Hiper düzlemin geometrik gösterimi

\section{Oylama}

Algoritmanın son aşamasında Tablo 7'de belirlenen kural çerçevesinde sinıflandırma sonuçları üzerinden oylama yapılmıştır. 
Tablo 7. Oylama aşamasinda Kullanilan kurallar (VB: Veri Bankasi)

\begin{tabular}{|c|c|}
\hline Kural-1 & $\begin{array}{l}\text { Eğer DVM sonucu } \\
\text { anormal ise kayit } \\
\text { anormaldir }\end{array}$ \\
\hline Kural-2 & $\begin{array}{l}\text { Eğer kNN sonucu } \\
\text { anormal ise kayıt } \\
\text { anormaldir }\end{array}$ \\
\hline Kural-3 & $\begin{array}{l}\text { Eğer SMT sonucu } \\
\text { anormal ise kayıt } \\
\text { anormaldir }\end{array}$ \\
\hline Kural-4 & $\begin{array}{l}\text { Eğer DVM ve kNN } \\
\text { sonucu anormal ise } \\
\text { kayıt anormaldir }\end{array}$ \\
\hline Kural-5 & $\begin{array}{l}\text { Eğer DVM veya SMT } \\
\text { sonucu anormal ise } \\
\text { kayıt anormaldir }\end{array}$ \\
\hline Kural-6 & $\begin{array}{l}\text { Eğer kNN veya SMT } \\
\text { sonucu anormal ise } \\
\text { kayılt anormaldir }\end{array}$ \\
\hline Kural-7 & $\begin{array}{l}\text { Eğer DVM, kNN veya } \\
\text { SMT sonucu anormal } \\
\text { ise kayıt anormaldir }\end{array}$ \\
\hline Kural-8 & $\begin{array}{l}\text { VB-a için Kural-7 } \\
\text { VB-b için Kural-6 } \\
\text { VB-c için Kural-1 } \\
\text { VB-d için Kural-7 } \\
\text { VB-e için Kural-2 } \\
\text { VB-f için Kural-3 }\end{array}$ \\
\hline
\end{tabular}

\section{Başarı Ölçütü}

Biyomedikal çalışmalarda tanı testi deneklerde hastalık olup olmadığını tespit etmede kullanılır. Tanı testi, test sonuçlarının deneğin gerçek durumu ile karşılaştırılarak yapılır. Tanı testi yapıldıktan sonra doğruluk, duyarlılık, özgüllük, pozitif ve negatif yorum gücü ile ROC eğrisinin altında kalan alan gibi parametreler hesaplanarak performans değerlendirilmesi yapılır (Wong ve Lim, 2011). Bir tanı testine ilişkin bütün olası sonuçlar Tablo 8'de verilmiştir. Testin tüm denekleri doğru tespit etme başarısını ifade eden doğruluk Denklem 1'de, sağlıklı bireyleri tespit etme başarısını ifade eden özgüllük Denklem 2'de ve sağlıksız bireyleri doğru tespit etme başarısını ifade eden duyarlılık ise Denklem 3'te verilmiştir.
Tablo 8. Bir tanı testinin tüm olası sonuçları

\begin{tabular}{|c|c|c|}
\hline \multirow[b]{2}{*}{$\begin{array}{l}\text { Tanı testi } \\
\text { Sonuçları }\end{array}$} & \multicolumn{2}{|c|}{ Gerçek Durum } \\
\hline & $\begin{array}{l}\text { Anormal } \\
\text { (Hastalıklı, } \\
\text { Pozitif) }\end{array}$ & $\begin{array}{l}\text { Normal } \\
\text { (Sağlıklı, } \\
\text { Negatif) }\end{array}$ \\
\hline $\begin{array}{l}\text { Anormal } \\
\text { (Hastalıklı, } \\
\text { Pozitif) }\end{array}$ & $\begin{array}{l}\text { Doğru Pozitif } \\
\text { (DP) }\end{array}$ & $\begin{array}{l}\text { Yanlış } \\
\text { Pozitif (YP) }\end{array}$ \\
\hline $\begin{array}{l}\text { Normal } \\
\text { (Sağlıklı, } \\
\text { Negatif) }\end{array}$ & $\begin{array}{l}\text { Yanlış Negatif } \\
(\mathrm{YN})\end{array}$ & $\begin{array}{l}\text { Doğru } \\
\text { Negatif (DN) }\end{array}$ \\
\hline doğruluk = & $\frac{D P+D N}{+Y P+D N+}$ & (1) \\
\hline özgüllük = & $\frac{D N}{+D N}$ & (2) \\
\hline luyarlılık & $\frac{D P}{P+Y N}$ & (3) \\
\hline
\end{tabular}

DN: Doğru negatif, YN: Yanlış negatif, DP: Doğru pozitif, YP: Yanlış pozitif

Tanı testi sonucu sağlıklı olarak teşhis edilmiş bir deneğin gerçekte de sağlıklı olma olasılığı şeklinde tanımlanan negatif yorum gücü (NPV) Denklem 4'de ve test sonucu sağlıksız olarak teşhis edilen bir deneğin gerçekte de sağlıksız olma olasılığ pozitif yorum gücü (PPV) Denklem 5'te verilmiştir.

$\mathrm{NPV}=\frac{D N}{D N+Y N}$
$\mathrm{PPV}=\frac{D P}{D P+Y P}$

NPV: Negatif yorum gücü, PPV: Pozitif yorum gücü

ROC analizi, klinik çalışmalarda tanı testinin sağlıklı (negatif) ve hastalıklı (pozitif) iki durumu ne kadar doğru bir şekilde ayırdığgnı ölçmede kullanılır. Analiz genellikle ROC eğrisi kullanılarak yapılır. ROC eğrisi, doğru pozitif oranının yanlış pozitif oranına göre 
değişiminin çizilmesiyle elde edilir. Eğrinin altında kalan alanın fazlalığı tanı testinin başarısını gösterir. ROC eğrisi altında kalan 0.9-1 arasinda ise tan1 testinin performans1 "Mükemmel", 0.8-0.9 arasında ise "Çok iyi", 0.7-0.8 arasında ise "İyi", 0.6-0.7 arasinda ise yeterli, 0.5-0.6 arasında ise "Kötü" ve 0.5'ten küçük ise "Kullanışsız" olarak nitelendirilir.

Yapılan yarışmada doğruluk yerine skor olarak adlandirılan ve duyarlılık ile özgüllügün aritmetik ortalamas1 kullanılmıştır. Sağlıklı bir karşılaştırma yapılabilmesi açısından bu çalışmada da skor değeri hesaplanmıştır (Liu vd., 2016).

\section{Uygulama ve Başarımlar}

$\mathrm{Bu}$ çalışmada Physionet.org tarafından 2016'da yapılan yarışmada kullanılan PCG kayıtları kullanılmıştır. Üç farklı sınıflandırıcı kullanılarak patolojik kayıtların tespit edilmesi amaçlanmıştır. Önerilen algoritmanın eğitilmesinde beş katlı çapraz doğrulama kullanılarak tüm verilerin hem eğitim hem de test için kullanılması sağlanmıştır. Elde edilen ortalama performans değerleri Tablo 9'da verilmiştir.

Tablo 9. Tanı testinin farklı kurallar kullanılarak elde edilen performans sonuçları

\begin{tabular}{cccccccc}
\hline Kural & $\begin{array}{c}\text { Doğruluk } \\
(\boldsymbol{\%})\end{array}$ & $\begin{array}{c}\text { Özgüllük } \\
(\boldsymbol{\%})\end{array}$ & $\begin{array}{c}\text { Duyarlılı } \\
(\boldsymbol{\%})\end{array}$ & $\begin{array}{c}\text { PPV } \\
(\boldsymbol{\%})\end{array}$ & $\begin{array}{c}\text { NPV } \\
(\boldsymbol{\%})\end{array}$ & $\begin{array}{c}\text { ROC } \\
(\boldsymbol{\%})\end{array}$ & $\begin{array}{c}\text { Skor } \\
(\boldsymbol{\%})\end{array}$ \\
\hline Kural-1 & 91.04 & 95.91 & 71.18 & 82.05 & 93.01 & 84.05 & 84.05 \\
Kural-2 & 92.58 & $\mathbf{9 7 . 8 6}$ & 72.18 & 89.72 & 93.15 & 85.02 & 85.02 \\
Kural-3 & $\mathbf{9 4 . 5 9}$ & 97.86 & 81.95 & $\mathbf{9 0 . 8 3}$ & 95.44 & 89.91 & 89.91 \\
Kural-4 & 91.34 & 95.14 & 76.69 & 80.31 & 94.04 & 85.91 & 85.91 \\
Kural-5 & 92.89 & 94.94 & 84.96 & 81.29 & 96.06 & 89.95 & 89.95 \\
Kural-6 & 94.43 & 96.50 & 86.47 & 86.47 & 96.50 & 91.48 & 91.48 \\
Kural-7 & 93.04 & 94.36 & $\mathbf{8 7 . 9 7}$ & 80.14 & 96.81 & 91.16 & 91.16 \\
Kural-8 & 94.28 & 95.91 & $\mathbf{8 7 . 9 7}$ & 84.78 & $\mathbf{9 6 . 8 7}$ & $\mathbf{9 1 . 9 4}$ & $\mathbf{9 1 . 9 4}$ \\
\hline
\end{tabular}

İlk üç kurala ait performans sonuçları sirasıyla destek vektör makineleri, $\mathrm{k}$ en yakın komşular ve sinıflandırıcı metotları toplulukları tek başına kullanıldığında elde edilen sonuçlara denk gelmektedir. $\mathrm{Bu}$ sonuçlar incelendiğinde hem doğruluk hem de skor anlamında en başarılı sonuçları sinıflandırıcı metotları topluluğu vermiştir. Ayrica, bu siniflandirıcı tüm tanı testleri içinde en yüksek doğruluk ve en yüksek pozitif yorum gücü elde edilmesini sağlamıştır. kNN sağlıklı denekleri en iyi teşhis ederken, sağlıksız denekler ise üç sınıflandırıcı bir arada kullanıldığında en iyi teşhis edilmiştir. Yarışma skoru, ROC eğrisi altında kalan alan ile negatif ve pozitif yorum gücü açısından bakıldığında ise kural-8 en iyi sonuçların elde edilmesini sağlamıştır. $\mathrm{Bu}$ durum her veri bankası için farklı özellik ve sınıflandırıcı seçiminin performans arttırıcı etkisini gözler önüne sermektedir. ROC eğrisi altında kalan alan incelendiğinde bütün kurallar mükemmel veya çok iyi bir performans sergilediği görülmektedir. Sekiz kurala ilişkin ROC eğrisi Şekil 9'da verilmiştir. Verilen ROC eğrileri, sadece 
algoritmanın farklı durumlarda performansinı karşılaştırılma amacıyla kullanıldığından her bir kural için çizdirilen ROC eğrileri

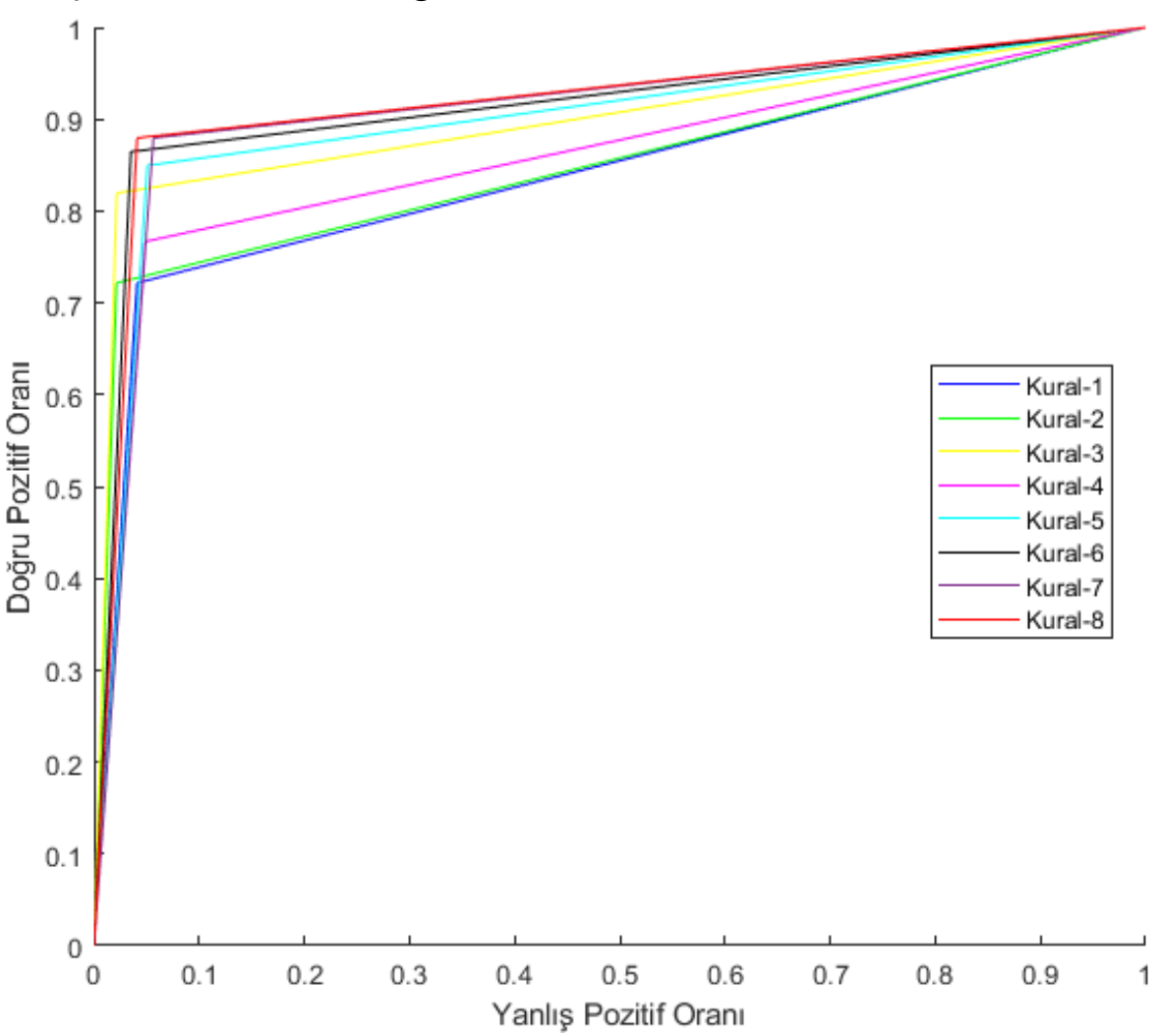

Şekil 9.Sekiz kurala ilişskin ROC ĕgrisi algoritmanın o kural için en iyi sonucu verdiği parametreler üzerinden çizdirilmiştir.
Elde edilen en iyi sonuçlar, yarışmada dereceye giren çalışmalar ile yarışma sonrası yapılan çalışmaların sonuçları Tablo 10'da verilmiştir.

Tablo 10. Farklı çalışmaların performans sonuçları

\begin{tabular}{llll}
\hline Çalışma & Duy & Özg & Doğ \\
\hline Potes vd. (2016) & 88.0 & 82.0 & 85.0 \\
Zabihi vd. (2016) & 94.2 & 88.8 & 91.5 \\
Kay ve Agarwal (2017) & 84.8 & 83.3 & 84.1 \\
\hline Whitaker vd. (2017) & 88.8 & 88.2 & 88.4 \\
Beritelli vd. (2018) & 93.0 & 91.0 & 92.0 \\
Langley ve Murray & 94.0 & 65.0 & 79.5 \\
(2017) & 95.9 & 90.5 & 93.2 \\
Homsi ve Warrick & 88.0 & 95.9 & 91.9 \\
$\begin{array}{l}\text { (2017) } \\
\text { Önerilen algoritma }\end{array}$ & & & \\
\hline
\end{tabular}

Tablo 10'da da görülebileceği üzere önerilen algoritma yarışmada dereceye giren çalışmalardan daha yüksek performans göstermiştir. Ayrıca, önerilen algoritma yarışma sonrasında aynı veriler ile yapılan çalışmalar ile kıyaslandığında bu çalışmalara oldukça benzer sonuçlar elde etmiştir.

\section{Sonuçlar ve Tartışma}

$\mathrm{Bu}$ çalışmada, Physionet.org tarafindan 2016'da yapılan yarışmaya kalp sesi kayıtları kullanılmıştır. Çalışmanın amacı patolojik kalp sesi kayitlarının segmantasyon yapılmadan, yani alt kalp seslerine ayrılmadan tespit edilmesidir. Bunun için altı adet veri bankasından alınan, farklı cihazlar ve vücudun farklı yerleri kullanılarak kaydedilen toplam 3240 adet PCG kaydı önişlem, özellik çıkarma-1, veri bankası sınıflandırması, özellik çıkarma-2, nihai sınıflandırma ve oylama aşamalarından 
geçirilerek DVM, kNN ve SMT kullanılarak sınıflandırılmıştır.

Algoritmanın eğitilmesinde ve test edilmesinde beşli çapraz doğrulama kullanılarak tüm verilerin hem eğitim aşamasında hem de test aşamasında kullanılması sağlanmıştır. Algoritmanın tanı testi performans sonuçları Tablo 9' da verilmiştir. Elde edilen sonuçlar göz önünde bulundurulduğunda algoritmanın oldukça başarılı sonuçlar elde ettiği görülmektedir. $\mathrm{Bu}$ yüzden, algoritmanın hekimlere ikinci bir görüş sağlamak amacıyla kullanılabileceği düşünülmektedir.

\section{Teșekkür}

$\mathrm{Bu}$ çalışma, Dicle Üniversitesi Bilimsel Araştırma Projeleri (DÜBAP) Koordinatörlüğü tarafindan 17.019 proje numarası ile desteklenmiştir.

\section{Kaynaklar}

Beritelli, F., Capizzi, G., Sciuto, G. L., Napoli, C. ve Scaglione, F., (2018). Automatic heart activity diagnosis based on Gram polynomials and probabilistic neural networks. Biomedical Engineering Letters, 8, 1, 77-85.

Homsi, M. N. ve Warrick, P., (2017). Ensemble methods with outliers for phonocardiogram classification. Physiological Measurement, 38, 8, 1631-1644.

Jain, A. ve Zongker, D., (1997). Feature selection: evaluation, application, and small sample performance. IEEE Transactions on Pattern Analysis and Machine Intelligence, 19, 2, 153158.

Johnston, M., (2007). The third heart sound for diagnosis of acute heart failure. Current Heart Failure Reports, 4, 3, 164-169.

Kay, E. ve Agarwal, A., (2017). DropConnected neural networks trained on time-frequency and inter-beat features for classifying heart sounds. Physiological Measurement, 38, 8, 1645-1657.

Langley, P. ve Murray, A., (2017). Heart sound classification from unsegmented phonocardiograms. Physiological Measurement, 38, 8, 1658-1670.

Lekram, B. ve Abhishek, M., (2014). Heart sound segmentation techniques: a survey. IOSR Journal of Electrical and Electronics
Engineering (IOSR-JEEE), 4, Electronics Eng., 46-49.

Liu, C., (2016). An open access database for the evaluation of heart sound algorithms. Physiological Measurement, 37, 12, 21812213.

Lubaib, P. ve Ahammed, V. D., (2015). The heart defect analysis based on PCG signals using pattern recognition techniques. Procedia Technology, 24, 2016, 1024 - 1031.

Maglogiannis, I., Loukis, E., Zafiropoulos, E. ve Stasis, A., (2009). Support Vectors Machinebased identification of heart valve diseases using heart sounds. Computer Methods and Programs in Biomedicine, 95, 1, 47-61.

Nabih-Ali, M., El-Sayed, A., Yahiba, A. 2017. A review of intelligent systems for heart sound. Journal of Medical Engineering \& Techology, 41, 7, 553-563.

Nigam, V. ve Priemer, R., (2007). A simplicitybased fuzzy clustering approach for detection and extraction of murmurs from the phonocardiogram. Physiological Measurement, 41, 7, 29-33.

Potes, C., Parvaneh, S., Rahman, A. ve Conroy, B., (2016). Ensemble of feature-based and deep learning-based classifiers for detection of abnormal heart sounds. 2016 Computing in Cardiology Conference (CinC), 621-624, Vancouver.

Schmidt, S. E., Holst-Hansen, C., Graff, C., Toft, E. ve Struijk, J. J., (2010). Segmentation of heart sound recordings by a durationdependent. Physiological Measurement, 3,4, 513-542.

Whitaker, B. M., Suresha, P. B., Liu, C., Clifford, G. D., Anderson, D. V. 2017. Combining sparse coding and time-domain features for heart sound classification. Physiological Measurement, 38, 8, 1701-1713.

Wong, H. B. ve Lim, G. H. 2011. Measures of diagnostic accuracy: sensitivity, specificity, PPV and NPV. International Federation of Clinical Chemistry and Laboratory Medicine, 19, 4, 316-318.

World Health Organization. The Impact of Chronic Disease In Turkey. http://www.who.int/chp/chronic_disease_repor t/turkey.pdf?ua=1. Yayın tarihi 2002. Erişim Tarihi Ekim 10, 2018.

Zabihi, M., Rad, A. B., Kiranyaz, S., Gabbouj, M. ve Katsaggelos, A. K., (2016). Heart sound anomaly and quality detection using ensemble of neural networks without segmentation. 2016 
Computing in Cardiology Conference (CinC), 613-616 Vancouver.

Zhongwei, J., Samjin, C., (2006). A cardiac sound characteristics waveform. Expert Systems with Applications, 31, 2, 286-298.
Zhukov, A., Tomin, N., Kurbatsky, V., Sidorov, D., Panasetsky, D. ve Foley, A., (2017). Ensemble methods of classification for power systems security assessment. Applied Computing and Informatics, 15, 2, 100-106. 


\section{Detection of pathological heart sound without segmentation by using SVM, kNN and ensemble methods of classification}

\section{Extended abstract}

Cardiovascular disorders or heart diseases are main culprit behind many deaths in the world. Every year, in Turkey, number of people dying due to heart diseases is more than number of people dying because of any other diseases.

In addition to advanced methods such as ECG, MRI, computed tomography and exercise test, there are simple methods like auscultate heart sounds. Furthermore, recently, many experts have been working on automatic heart diseases detection techniques based on machine learning.

Phonocardiogram (PCG) is non-stationary and complex signal which is recorded by an electronic stethoscope and converted to digital signal. PCGs are formed by physical activity of body and contain useful information for heart diseases detection. A PCG may consists of four heart sounds called S1, S2, S3 and S4, and abnormal sounds called murmur which indicates abnormality.

In this work, Training set of Physionet.org 2016 challenge is used to develop, train and test an algorithm that can detect pathological or abnormal heart sounds. This set contains 3240 $P C G$ recordings which 2514 of them are normal and 662 of them are abnormal from six databases around the world. Different body location and devices are used when these databases are created. In order minimize negative effects of these differences, one additional classification phase is added to the algorithm. Therefore, the algorithm consists of six phase which are preprocess, feature extraction-1, database classification, feature extraction-2, ultimate classification and voting.

In preprocess phase, PCG recordings are denoised by a special technique developed by Schmidt at al. (2010) and normalized by minmax normalization.

In feature extraction-1 phase, statistical features (minimum, maximum, mean, median, skewness, kurtosis, RMS, ratio of $R M S$ to maximum) of frequency domain between $0-200 \mathrm{~Hz}$ and 800 $1000 \mathrm{~Hz}$ of signal that is calculated by fast
Fourier transform $(F F T)$ are calculated $(8 \times 2=$ 16 features) to feed input of database classifier.

In database classification phase, $P C G$ recordings are classified by ensemble method of classifier $(E M C)$ as per databases which are recordings obtained from. Therefore, different features can be extracted; different classifier can be trained and tested for different databases. Parameters of ensemble classifier are as flow: algorithm used to ensemble weak classifiers is AdaBoostM2, weak classifier is decision tree, number of weak classifier is 487 and learning rate is 0.4591 .

In feature extraction-2 phase, RMS, zero crossing rate, skewness, kurtosis, mean, standard deviation, variance, entropy, maximum, median and total harmonic distortion of frequency domain are calculated. Same statistical features given above except median and total harmonic distortion of detail and approximation coefficients of third and fourth level discrete wavelet transform are extracted. Same statistical feature given above except zero crossing rate, median and total harmonic distortion of mel frequency cepstrum coefficients are calculated. After feature extraction, sequential forward feature selection is applied, and number of features is reduced.

In ultimate classification phase, three classifiers (SVM, kNN and ensemble of classification) for each database, total 18 classifiers are trained to detect abnormal heart sound recordings.

In voting phase, predefined rules are used to vote each classifier results. Rule acquired best performance is as follow: for database-a: "if any result of classifier is abnormal then recording is abnormal", for database-b: "if result of $k N N$ or EMC is abnormal then recording is abnormal", for database-c: "if result of SVM is abnormal then recording is abnormal", for database-d: same as database-a, for database-e: "if result of $k N N$ is abnormal then recording is abnormal", for database-f: "if result of EMC is abnormal then recording is abnormal".

An accuracy of $94.28 \%$, a specificity of $95.91 \%$, a sensitivity of $87.97 \%$, a PPV of $84.78 \%$, a NPV of $96.87 \%$, area under ROC curve $91.94 \%$ and a score of $91.94 \%$ are best result obtained. These results are better than first three entries of challenge and very close to work completed after challenge.

Keywords: Heart sound, PCG, Fourier transform, MFCC, SVM, kNN, EMC, Classification 